\title{
Systemic Stress in the EU under the COVID-19 Pandemic: the Impact of ECB Monetary Policy Decisions
}

\author{
Mukhametov O.R." \\ Financial Research Institute of the Ministry of Finance of the Russian Federation, Moscow 127006, Russian Federation \\ *Corresponding author. Email: omukhametov@nifi.ru
}

\begin{abstract}
After the announcement of the COVID-19 pandemic the volatility in financial markets has increased significantly, which has caused the intensification of the systemic financial stress in the EU countries. European central bank (ECB) has taken several measures, including expanding asset purchase programs to mitigate the negative effects of the coronavirus crisis. The significant increase in asset purchases has stabilized financial markets, which returned to pre-crisis levels after a surge in volatility. This paper examines the impact of ECB extended quantitative easing on indicator of systemic financial stress in EU countries. The paper presents a panel vector autoregression (PVAR), which includes the indicator of systemic stress and the change in the balance sheet of the Eurosystem as the endogenous variables. The analysis has demonstrated that changes in the volume of asset purchases did not have a statistically significant effect on the indicator of systemic stress. However, these results can inevitably be considered only as preliminary, since a more detailed study requires a longer and more structured time series.
\end{abstract}

Keywords: systemic stress, yield curve, ECB, quantitative easing, panel vector autoregression

\section{INTRODUCTION}

The pandemic of the new coronavirus infection COVID-19 has become a source of the serious financial stress. Due to the rapid growth of new cases of infection, as well as the introduction of the significant restrictive measures in major advanced and emerging economies, financial markets have reacted with increased volatility. In particular, the VIX index has rose significantly, while the yields on government bonds of both advanced and emerging economies have increased. Furthermore, the increase in credit default swaps (CDS) has been recorded. The real sector has fell victim to the increased unemployment and a drop in industrial production. Most of the world's largest economies have declined about $10 \%$ in aggregate output in the second quarter of 2020, and further recovery will inevitably be more modest amid new restrictive measures that are necessary to combat the spread of the virus.

To mitigate the negative effects of the coronavirus pandemic, both governments and central banks around the world have adopted massive support packages. It should be noted that central banks reacted to the negative effects of the pandemic immediatly. In particular, the US Federal Reserve and the European Central Bank (ECB) announced the expansion of asset purchase programs and the launch of swap lines and long-term refinancing operations to provide markets with additional liquidity. The governments launched programs to support employment and income of the population. For instance, the additional social payments were organized for the certain groups of the population, the unemployment benefits have been increased, and enterprises have received the access to cheaper loans and subsidies. For example, the Kurzarbeit program implemented in Germany is considered as one of the most effective in terms of maintaining employment during the crisis. This support measure assumes that the government co-finances the labor costs of enterprises.

Large-scale measures to stimulate the economy have been taken by the European Central Bank (ECB). In particular, the regulator has launched the $€ 1,350$ bln pandemic emergency purchase program (PEPP) and extended asset purchase program. In addition, ECB has announced a new pandemic emergency longer-term refinancing operation (PELTROs) and has reduced the interest rate on targeted longer-term refinancing operations (TLTRO III) by 25 basis points to $-0.5 \%$ from June 2020 to June 2021 .

Several studies have already analyzed the impact of the coronavirus crisis on economic indicators, as well as evaluated the fiscal and monetary policy measures taken during the pandemic. In particular, He $\mathrm{Z}$. et al. have examined the effect of the pandemic on the yield curve of US Treasuries [1], Pang R. K. K. et al. have analyzed the relationship between the spread of the virus and the public debt market in Europe [2]. In addition, Sène B. et al. [3] have studied the reaction of advanced and emerging economies government bond yield curves to the rise in new cases of COVID-19 infection. The negative reaction of stock exchanges in response to the introduction of restrictive measures in different countries of the world has been investigated by Ashraf B. N. [4]. 
Despite the fact that the several papers have already focused on the reaction of financial markets, certain aspects remain poorly understood. In particular, the analysis of the impact of the measures taken by the ECB on sovereign stress in the EU economies has not been considered yet. This study focuses on this issue.

\section{METHODOLOGY}

This paper examines the impact of the measures taken by the ECB (i.e. the expansion of asset purchases including PEPP) on systemic stress in the EU economies. The Composite Indicator of Systemic Stress (CISS) was developed by ECB economists. It is based on assessing the systemic financial stress across five key areas, including banks and non-bank financial intermediaries, money markets, bond and equity markets, and foreign exchange markets. Hollo D. et al. indicates that CISS includes five sub-indices (according to the key directions) calculated using indicators of agents' uncertainty, information asymmetry, and investor disagreement [5].

The first step of this research is to graphically analyze the reaction of the yield curve to the spread of the pandemic and the measures taken in Europe. This analysis is needed to outline some basic facts about the reaction of financial markets to the epidemiological situation and the ECB's monetary policy measures. In addi5tion, this stage of the research considers the dynamics of the indicator of systemic stress during the year 2020. Graphical analysis in this case provides some basic ideas about the impact of the coronavirus crisis and ECB measures on the state of systemic stress in Europe.

At the second stage, a panel vector autoregression (PVAR) has been used to assess the impact of ECB measures on the indicator of systemic stress in the EU countries. PVAR model can be presented in the following form:

$Y_{i, t}=\Gamma_{0}+\Gamma(L) Y_{i, t}+v_{i}+d_{c, t}+\varepsilon_{i, t},(1)$

where $Y_{i, t}$ is a vector of endogenous variables, $\Gamma_{0}$ is a vector of constants, $\Gamma(L)$ is a matrix polynomial in the lag operator, $v_{i}$ are country-specific fixed effects, $d_{c, t}$ are country-specific time effects, and $\varepsilon_{i, t}$ is a vector of error terms [6].

Canova F. and Ciccarelli M. have underscored several advantages of PVAR [7]. First, PVAR are able to capture both static and dynamic interdependencies. Second, PVAR can be used to handle relationships between units without constraints. Third, it is easy to account for the time variation of the coefficients and dispersion of shocks. Fourth, PVAR allows to account for the dynamic inhomogeneities in the cross section. PVAR is a widely used instrument for empirical analysis in macroeconomics, banking and finance, as well as in the international economy. Thus, PVAR is considered as a suitable method for the further analysis.

The sample used includes 17 EU countries (Austria, Belgium, Czech Republic, Germany, Denmark, Spain, Finland, France, Greece, Hungary, Ireland Italy,
Netherlands, Poland Portugal, Sweden), United Kingdom and euro area. The data on CISS, as well as the data on changes in the Eurosystem balance sheet has been used. First, a model has been fitted on a wider sample, which covers the period from September 2000 to August 2020 (panel A). The second model has been fitted from observations for the year 2020 only (panel B). The preliminary procedures required to fit a PVAR will be described in the research results section.

\section{RESULTS}

At the first stage, a visual analysis of the dynamics of government bond yields in the euro zone has been implemented (Figure 1). The graph shows, that during the initial period of the coronavirus crisis, government bond yields have rose sharply, reflecting increased investment risks. Further, the yield curve has been characterized by increased volatility. At the same time, it was possible to avoid a steady upward trend in profitability, probably due to the measures taken by the ECB. For example, eventanalysis by Hartley J. S., Rebucci A. have showed that on the second and third days after the ECB's announcement of the launch of PEPP, the yields of 10-year government bonds decreased statistically significantly [8]. A similar trend has been observed in other advanced and emerging economies, where central banks have moved to the quantitative easing during the crisis.

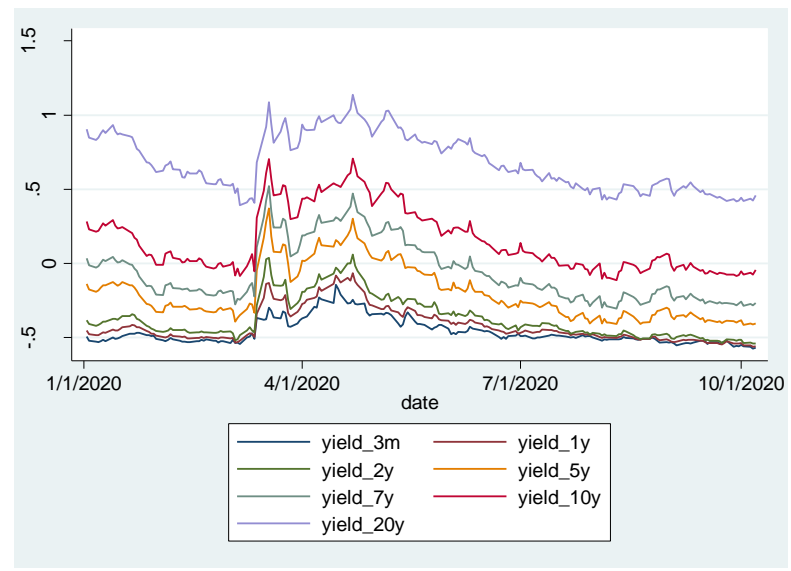

Figure 1 The EU countries government bonds yield curve

Next, the CISS dynamics for the eurozone, as well as for the largest countries, including Germany, France and Italy has been examined (Figure 2). As the graph shows, after the coronavirus pandemic has been announced in March, the systemic stress in the eurozone have rose sharply. In Italy, the peak of systemic stress was observed in April, while in other countries and the eurozone, the indicator has showed a decline. The dynamics of the CISS suggests that the expansion of the ECB's stimulus measures put downward pressure on systemic stress. 


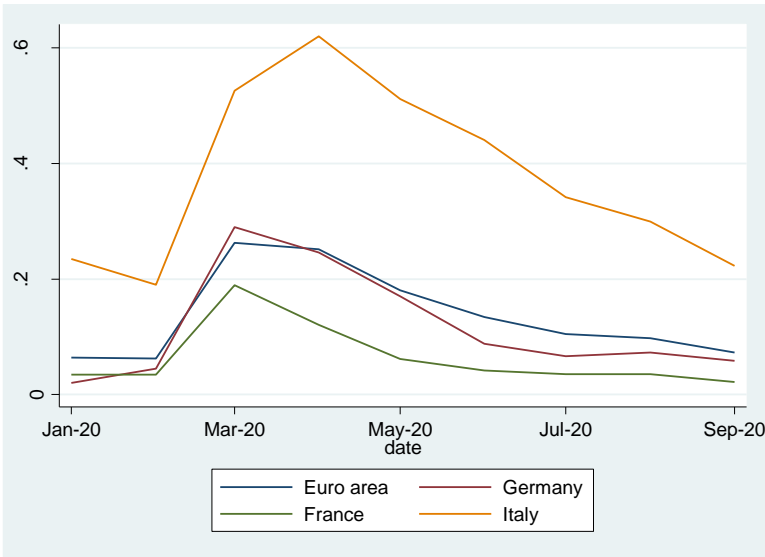

Figure 2 The EU countries CISS dynamics (JanuarySeptember 2020)

The dynamics of the Eurosystem balance sheet is shown in Figure 3. As follows from the graph, asset purchases in March and April have demonstrated the highest growth rates since the launch of quantitative easing (October 2014). The increase in purchases of government and corporate assets has been accompanied by a decrease in both the yield of European government bonds and the indicator of systemic stress in the EU countries. Further stage of this research examines the relationship between systemic stress and ECB measures using PVAR.

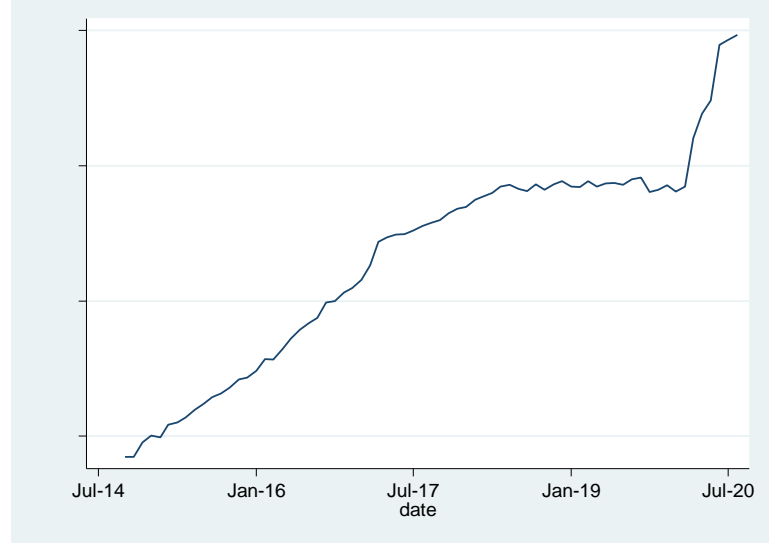

Figure 3 The Eurosystem balance sheet dynamics (October 2014-August 2020)

The data explored within this research has been divided into two panels. Panel A covers monthly data on the CISS and Eurosystem balance sheet (ESBS) change from September 2000 to August 2020, while Panel B includes monthly data on the same variables from the January to August 2020. Thus, two PVAR have been fitted. The next part of the paper describes procedures implemented to fit PVAR using each of the panels.

Before the fitting of the PVAR, the Im-Pesaran-Shin unitroot test has been used [9]. This test evaluates the stationarity of the time series included in the model. The null hypothesis of the Im-Pesaran-Shin unit-root test assumes that all panels contain unit roots. An alternative hypothesis of the test is that some panels are stationary. Table 1 shows the test results for 8 lags for each of the variables used (Panel A). The results indicate that time series are stationary.

Table 1 Im-Pesaran-Shin unit-root test results (Panel A)

\begin{tabular}{|l|l|l|l|}
\hline Variable & Number of lags & Statistic & P-value \\
\hline CISS & No lags & -4.0657 & 0.0000 \\
\hline \multirow{5}{*}{} & 1 lag & -4.2931 & 0.0000 \\
\cline { 2 - 4 } & 2 lags & -4.0079 & 0.0000 \\
\cline { 2 - 4 } & 3 lags & -3.6622 & 0.0001 \\
\cline { 2 - 4 } & 4 lags & -3.2538 & 0.0006 \\
\cline { 2 - 4 } & 5 lags & -2.9633 & 0.0015 \\
\cline { 2 - 4 } & 6 lags & -2.8188 & 0.0024 \\
\cline { 2 - 4 } & 7 lags & -2.9759 & 0.0015 \\
\cline { 2 - 4 } & 8 lags & -3.0897 & 0.0010 \\
\hline \multirow{5}{*}{ ESBS_change } & No lags & -37.0754 & 0.0000 \\
\hline & 1 lag & -28.6899 & 0.0000 \\
\cline { 2 - 4 } & 2 lags & -11.7587 & 0.0000 \\
\cline { 2 - 4 } & 3 lags & -13.4263 & 0.0000 \\
\cline { 2 - 4 } & 4 lags & -15.8617 & 0.0000 \\
\cline { 2 - 4 } & 5 lags & -9.0866 & 0.0000 \\
\cline { 2 - 4 } & 6 lags & -9.7897 & 0.0000 \\
\cline { 2 - 4 } & 7 lags & -8.8225 & 0.0000 \\
\cline { 2 - 4 } & 8 lags & -8.4129 & 0.0000 \\
\hline
\end{tabular}

Further, three model-selection criteria have been calculated to select the optimal number of lags. The values of the criteria (MBIC, MAIC, MQIC) are given in Table 2. In accordance with the results obtained, the third-order 
PVAR has been selected, since this number of lags has the smallest values of the criteria. The second-order PVAR reject the Hansen's overidentification restriction at the 5\% statistical significance level, reflecting possible misspecification in the model.

Table 2 Model-selection criteria values (Panel A)

\begin{tabular}{|r|ccrrrr|}
\hline lag & CD & J & J pvalue & MBIC & MAIC & MQIC \\
\hline 1 & .9277087 & 149.6294 & $6.74 e-26$ & 49.88082 & 125.6294 & 98.80348 \\
2 & .9317298 & 19.62175 & .0118658 & -46.87729 & 3.621752 & -14.26218 \\
3 & .9411002 & 46.66741 & $1.79 e-09$ & 13.41789 & 38.66741 & 29.72544 \\
4 & .9454364 &. &. & &. &. \\
\hline
\end{tabular}

The next procedure is the PVAR fitting. The third-order PVAR model has been fitted, while the first four lags of endogenous variables have been used as instruments because this minimizes each of the model-selection criteria. The coefficients of PVAR are presented in Table 3 . They cannot be interpreted meaningfully; for this, the impulse response functions will be constructed further.

Table 3 PVAR coefficients estimates (Panel A)

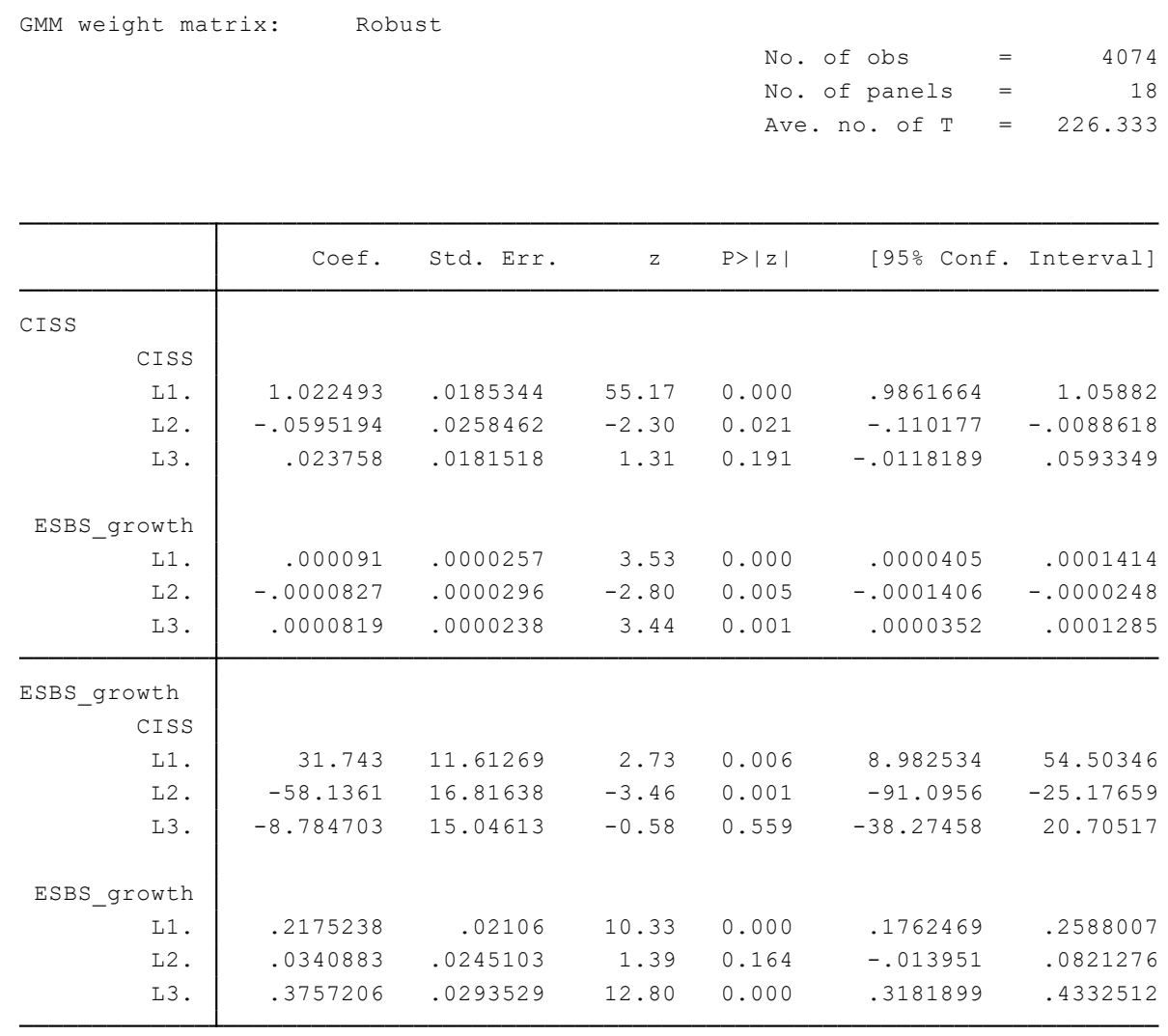

Instruments : $1(1 / 4)$. (CISS ESBS growth)

Granger causality test statistics do not reject the hypothesis that any variable used does not Granger-cause another variable (Table 4). Table 5 and Figure 4 suggest that
PVAR using Panel A is stable and impulse response functions (IRFs) and forecast-error variance decomposition can be calculated (FEVDs). 
Table 4 Granger-causality Wald test results (Panel A)

\begin{tabular}{|c|c|c|c|}
\hline Equation \Excluded & chi2 & $d f$ & Prob > chi2 \\
\hline \multicolumn{4}{|l|}{ CISS } \\
\hline ESBS_growth & 28.922 & 3 & 0.000 \\
\hline ALL & 28.922 & 3 & 0.000 \\
\hline \multicolumn{4}{|l|}{ ESBS_growth } \\
\hline CISS & 48.142 & 3 & 0.000 \\
\hline ALL & 48.142 & 3 & 0.000 \\
\hline
\end{tabular}

Table 5 PVAR stability condition test (Panel A)

\begin{tabular}{|rr|r|}
\hline \multicolumn{2}{|c|}{ Eigenvalue } & \\
\hline \multicolumn{1}{|c|}{ Real } & Imaginary & \multicolumn{1}{c|}{ Modulus } \\
\hline .9760824 & 0 & .9760824 \\
.8345363 & 0 & .8345363 \\
-.2972373 & -.6026119 & .6719309 \\
-.2972373 & .6026119 & .6719309 \\
.0119365 & -.1615066 & .1619471 \\
.0119365 & .1615066 & .1619471 \\
\hline
\end{tabular}

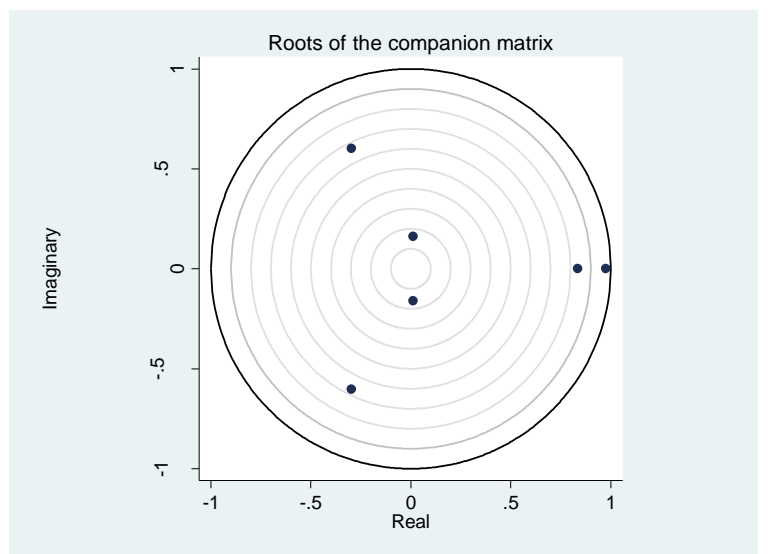

Figure 4 Graph of eigenvalue stability condition (Panel A)

Orthogonalized IRFs are presented in Figure 5. FEVDs are presented in Table 6. The IRF confidence intervals are calculated using 200 Monte Carlo draws from the distribution of the fitted reduced-form PVAR, as it done in the paper of Abrigo M.R.M. and Love I. [10]. IRFs indicates that the change in ESBS have not affect the CISS and, thus, the quantitative easing program has not been resulted in systemic stress reduction.

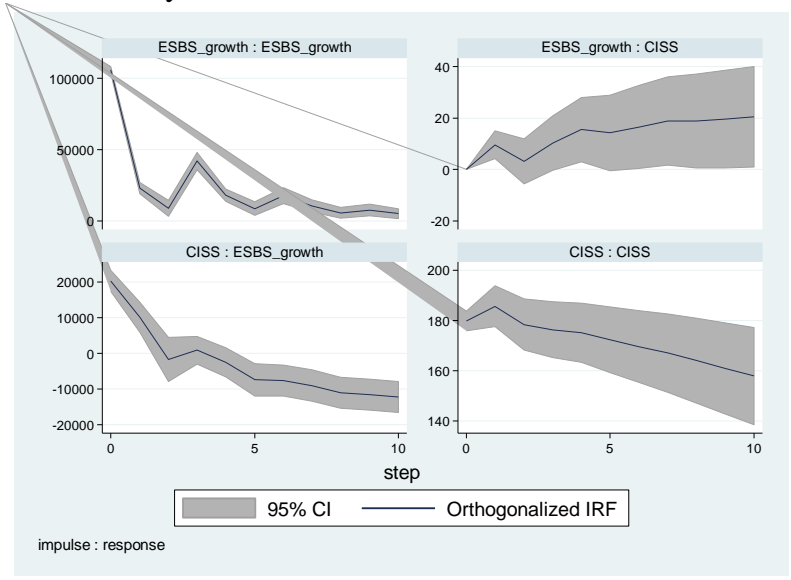

Figure 5 Graphs of orthogonalized IRFs (Panel A) 
Table 6 Forecast-error variance decomposition (Panel A)

\begin{tabular}{|c|c|c|}
\hline $\begin{array}{l}\text { Response } \\
\text { variable } \\
\text { and } \\
\text { Forecast } \\
\text { horizon }\end{array}$ & $\begin{array}{r}\text { Impulse } \\
\text { CISS }\end{array}$ & $\begin{array}{l}\text { variable } \\
\text { ESBS_growth }\end{array}$ \\
\hline \multicolumn{3}{|l|}{ CISS } \\
\hline 0 & 0 & 0 \\
\hline 1 & 1 & 0 \\
\hline 2 & .9986165 & .0013836 \\
\hline 3 & .9989598 & .0010402 \\
\hline 4 & .9984006 & .0015994 \\
\hline 5 & .9972162 & .0027837 \\
\hline 6 & .9965943 & .0034058 \\
\hline 7 & .9957948 & .0042053 \\
\hline 8 & .9948407 & .0051593 \\
\hline 9 & .9940642 & .0059358 \\
\hline 10 & .9933057 & .0066942 \\
\hline \multicolumn{3}{|l|}{ ESBS_growth } \\
\hline 0 & 0 & 0 \\
\hline 1 & .0356647 & .9643353 \\
\hline 2 & .0422137 & .9577864 \\
\hline 3 & .0421558 & .9578443 \\
\hline 4 & .0369301 & .9630699 \\
\hline 5 & .0364904 & .9635096 \\
\hline 6 & .0399188 & .9600812 \\
\hline 7 & .0427999 & .9572001 \\
\hline 8 & .0476225 & .9523774 \\
\hline 9 & .0551638 & .9448362 \\
\hline 10 & .0631372 & .9368627 \\
\hline
\end{tabular}

These results have been gained using Panel $\mathrm{A}$, which covers longer time series. Tables 6-10 and Figures 6-7 below demonstrates the results of the same procedures and tests (Im-Pesaran-Shin unit-root test, PVAR fitting, Granger-causality Wald test, stability condition test, IRFs and FEDs computation) using Panel $\mathrm{B}$, which includes monthly data from January to August 2020. The first-order
PVAR has been fitted. IRFs graphs show that there has not been statistically significant response of systemic risk to the growth of ESBS. However, these results can inevitably be considered only as preliminary, since a more detailed study requires a longer and more structured time series.

Table 6 Im-Pesaran-Shin unit-root test results (Panel B)

\begin{tabular}{|c|c|c|c|}
\hline Variable & Number of lags & Statistic & P-value \\
\hline \multirow{2}{*}{ CISS } & No lags & -1.9503 & 0.0256 \\
\cline { 2 - 4 } & 1 lag & -8.8115 & 0.0000 \\
\cline { 2 - 4 } & 2 lags & -3.4177 & 0.0003 \\
\hline ESBS_change & No lags & -4.2460 & 0.0000 \\
\cline { 2 - 4 } & 1 lag & -10.0505 & 0.0000 \\
\cline { 2 - 4 } & & -1.6221 & 0.0524 \\
\cline { 2 - 4 } & 2 lags & & \\
\hline
\end{tabular}


Table 7 PVAR coefficients estimates (Panel B)

$\begin{array}{llr}\text { No. of obs } & & 108 \\ \text { No. of panels } & & 18 \\ \text { Ave. no. of T } & = & 6.000\end{array}$

\begin{tabular}{r|rccccc}
\hline & Coef. & Std. Err. & $z$ & P $|z|$ & [95\% Conf. Interval] \\
\hline CISS & & & & & \\
CISS & & & & & \\
L1. & 1.342064 & .238077 & 5.64 & 0.000 & .8754412 & 1.808686 \\
ESBS_growth & & & & & & \\
L1. & -.0000219 & .000011 & -1.99 & 0.046 & -.0000434 & $-3.54 e-07$ \\
\hline ESBS_growth \\
CISS \\
L1.
\end{tabular}

Table 8 Granger-causality Wald test results (Panel B)

\begin{tabular}{|c|c|c|c|}
\hline Equation $\backslash$ Excluded & chi2 & $d f$ & Prob > chi2 \\
\hline \multicolumn{4}{|l|}{ CISS } \\
\hline ESBS_growth & 3.969 & 1 & 0.046 \\
\hline ALL & 3.969 & 1 & 0.046 \\
\hline \multicolumn{4}{|l|}{ ESBS_growth } \\
\hline CISS & 9.174 & 1 & 0.002 \\
\hline ALL & 9.174 & 1 & 0.002 \\
\hline
\end{tabular}

Table 9 PVAR stability condition test (Panel B)

\begin{tabular}{|c|c|c|}
\hline \multicolumn{2}{|c|}{ Eigenvalue } & \multirow[b]{2}{*}{ Modulus } \\
\hline Real & Imaginary & \\
\hline 1.182043 & 0 & 1.182043 \\
\hline-.2496903 & 0 & .2496903 \\
\hline
\end{tabular}

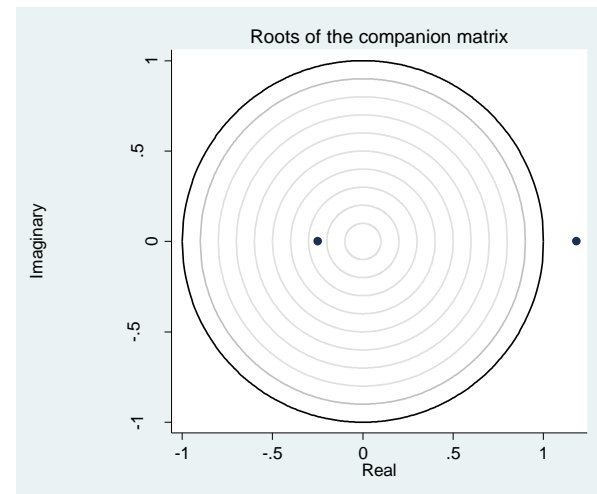

Figure 6 Graph of eigenvalue stability condition (Panel B)

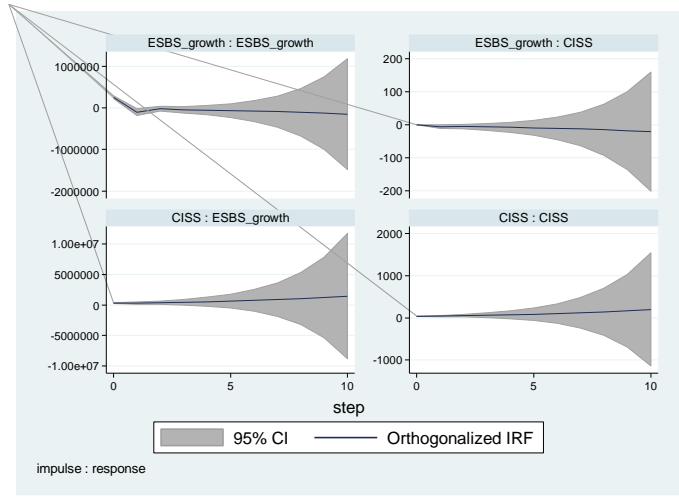

Figure 7 Graphs of orthogonalized IRFs (Panel B) 
Table 10 Forecast-error variance decomposition (Panel B)

\begin{tabular}{|c|c|c|}
\hline $\begin{array}{l}\text { Response } \\
\text { variable } \\
\text { and } \\
\text { Forecast } \\
\text { horizon }\end{array}$ & $\begin{array}{r}\text { Impulse } \\
\text { CISS }\end{array}$ & $\begin{array}{l}\text { variable } \\
\text { ESBS_growth }\end{array}$ \\
\hline \multicolumn{3}{|l|}{ CISS } \\
\hline 0 & 0 & 0 \\
\hline 1 & 1 & 0 \\
\hline 2 & .9910573 & .0089427 \\
\hline 3 & .9907596 & .0092404 \\
\hline 4 & .9901866 & .0098134 \\
\hline 5 & .9899506 & .0100494 \\
\hline 6 & .9897898 & .0102102 \\
\hline 7 & .9896897 & .0103104 \\
\hline 8 & .9896222 & .0103777 \\
\hline 9 & .9895766 & .0104234 \\
\hline 10 & .989545 & .010455 \\
\hline \multicolumn{3}{|l|}{ ESBS_growth } \\
\hline 0 & 0 & 0 \\
\hline 1 & .6053612 & .3946388 \\
\hline 2 & .7248264 & .2751737 \\
\hline 3 & .8211613 & .1788386 \\
\hline 4 & .8759797 & .1240204 \\
\hline 5 & .9119264 & .0880736 \\
\hline 6 & .9356254 & .0643747 \\
\hline 7 & .9517567 & .0482434 \\
\hline 8 & .962881 & .0371191 \\
\hline 9 & .9706418 & .0293582 \\
\hline 10 & .9760958 & .0239042 \\
\hline
\end{tabular}

\section{DISCUSSION}

Thus, this study showed that the indicator of systemic stress in the EU countries have not show a statistically significant response to the growth of the Eurosystem balance sheet. On the one hand, this result is unexpected, since the indicator of system stress includes, among other things, the indicators of the government bond yield curve, which statistically significantly respond to decisions on monetary policy. On the other hand, the indicator of systemic stress also covers other segments of the financial sector, which are less sensitive to the decisions of the ECB.

Moreover, the analysis performed has obvious limitations. First, to assess the effects of quantitative mitigation, a PVAR with two endogenous variables was constructed. Other studies in this area have operated on panel vector autoregression with exogenous variables (PVARX). For example, M. Kremer considered the macroeconomic effects of financial stress by including exogenous variables of monetary policy into the model [11]. Therefore, further research may enrich the proposed baseline model with additional variables that are important in terms of understanding the nature of systemic financial stress. In particular, the study of the relationship between monetary policy and systemic stress during a pandemic is likely to need to be done with epidemiological evidence in mind. Second, the analysis of the effect of quantitative mitigation on systemic stress during a pandemic is limited in the article to a very short period of only eight months. Given that the pandemic is ongoing at the time of this paper writing and the future actions of central banks and governments are being actively discussed in the public field, new actions can be expected with regard to asset purchase programs. This will extend the analyzed period and obtain more stable estimates.

It should be noted that the results obtained in the article may be useful for economies that have not yet tested quantitative easing as a monetary policy instrument. On the one hand, it is known that asset purchase programs (government bonds and in some cases corporate securities) reduced the cost of borrowing and, to a limited extent, stimulated inflation increase. On the other hand, as follows from the results obtained, such a policy does not necessarily lead to a decrease in systemic financial stress. This is probably since a decrease in interest rates and an active acquisition of assets by the central bank is fraught with increased risks of financial instability. In particular, 
in the absence of adequate prudential supervision, a sharp accumulation of debt can occur, while the marginality of banking in an environment of near-zero interest rates is very low.

Accordingly, the results obtained can be considered as a starting point for further modeling the relationship between systemic financial stress and unconventional monetary policy. The more detailed modeling requires the inclusion of new variables in a model like PVAR.

\section{CONCLUSION}

Thus, the PVAR with two endogenous variables demonstrated that an increase in asset purchases by a central bank (ESBS change) does not lead to a statistically significant change in the indicator of systemic financial stress (CISS). The main reason is probably related to the fact that quantitative easing can potentially pose risks to financial stability, although it has a positive impact on inflation and lower borrowing costs. Hence, further analysis requires expanding the list of variables, including the possible inclusion of exogenous variables, which will allow obtaining more accurate estimates.

\section{REFERENCES}

[1] Z. He et al, Treasury inconvenience yields during the covid-19 crisis, National Bureau of Economic Research, 2020.

[2] R. K. K. Pang et al, An analysis of network filtering methods to sovereign bond yields during COVID-19, arXiv, 2020.

[3] B. Sène et. al, Overshooting of sovereign emerging eurobond yields in the context of COVID-19, Finance research letters (2020) 1017-1046. DOI:

https://doi.org/10.1016/j.frl.2020.101746

[4] B. N. Ashraf, Economic impact of government interventions during the COVID-19 pandemic: International evidence from financial markets, Journal of Behavioral and Experimental Finance 27 (2020). DOI: https://doi.org/10.1016/j.jbef.2020.100371

[5] Kremer M. et al, CISS-a composite indicator of systemic stress in the financial system, ECB, 2012.

[6] F. Jawadi et al, Fiscal and monetary policies in the BRICS: A panel VAR approach, Economic Modelling 58 (2016) 535-542. DOI: https://doi.org/10.1016/j.econmod.2015.06.001

[7] F. Canova, M. Ciccarelli, Panel vector autoregressive models: A survey, ECB, 2013.
[8] J. S. Hartley, A. Rebucci, An Event Study of COVID-19 Central Bank Quantitative Easing in Advanced and Emerging Economies, National Bureau of Economic Research, 2020.

[9] K. S. Im et. al, Testing for unit roots in heterogeneous panels, Journal of econometrics 1(115) (2003) 53-74. DOI: https://doi.org/10.1016/S03044076(03)00092-7

[10] M. R. M. Abrigo, I. Love, Estimation of panel vector autoregression in Stata, The Stata Journal 16(3) (2016) 778-804. DOI: https://doi.org/10.1177/1536867X1601600314

[11] M. Kremer, Macroeconomic effects of financial stress and the role of monetary policy: a VAR analysis for the euro area, International Economics and Economic Policy 13(1) (2016) 105-138. DOI: https://doi.org/10.1007/s10368-015-0325-z 